\title{
Direct observation of a doubly destabilized cation
}

\section{Hanan Afifi, Alexandre Mikhailine, ${ }^{a}$ Gabriela Mladenova, ${ }^{a}$ Andrei Chtchemelinine, Israt Sultana, ${ }^{\mathrm{a}}$ Tatiana Dyblenko, ${ }^{\mathrm{a}}$ Evgeny Danilov, ${ }^{\mathrm{b}}$ Rene Fournier, ${ }^{\mathrm{a}}$ and Edward Lee-Ruff ${ }^{* a}$}

${ }^{a}$ Department of Chemistry, York University, Toronto, Ontario, Canada, M3J 1P3

${ }^{b}$ Center for Photochemical Sciences, Department of Chemistry, Bowling Green State University

141 Overman Hall, Bowling Green, OH 43403

E-mail: leeruff@yorku.ca

\begin{abstract}
The 9-fluorenyl cation is a member of the $4 N$ Hückel antiaromatic series of intermediates, first observed by time-resolved spectroscopy on UV photo-excitation of 9-fluorenol. ${ }^{[1]}$ 9Trifluoromethyl-9-fluorenol incorporating an electron-withdrawing substituent was subjected to preparative and laser flash photolysis. Photoproduct studies in methanol indicated products derived from the corresponding fluorenyl cation and radical intermediates. Time-resolved spectroscopy in hexafluoroisopropanol (HFIP) showed a transient which was assigned to the corresponding cation as evident from methanol quenching. The lifetimes and methanol quenching rates of this transient was compared with that of 9-methylfluorenyl cation. The kinetic stabilities of these ions were compared to thermodynamic parameters obtained from theoretical calculations.
\end{abstract}

Keywords: Fluorenyl cations, fluorenyl radicals, laser flash photolysis, destabilized carbocations

\section{Introduction}

Carbocations incorporated in destabilizing configurations have been well investigated in terms of angular distortions, ${ }^{1}$ incorporation into antiaromatic electronic configurations ${ }^{2}$ and substituent effects. ${ }^{3}$ The placement of a carbocation center involving two of these factors gives rise to enhanced destabilized carbocations. ${ }^{4}$ Specifically, 1,3-cyclopentadienylium, indenylium, fluorenylium cations to which an electron-withdrawing substituent such as trifluoromethyl is bonded have been referred to as "doubly destabilized" carbocations, and have been the subject of solvolytic and theoretical studies. ${ }^{4 a, b, d}$ The 9-fluorenylium cation can be conveniently generated by photoexcitation of the corresponding 9-fluorenol derivatives. ${ }^{2 b, c}$ These cations have not been directly observed in previous studies, and their kinetic stabilities (nucleophile quenching rates) 
not measured. In order to directly observe these species and compare relative reactivities of the "doubly destabilized" cation A with the corresponding isostere, 9-methylfluorenylium B, we carried out the laser flash and continuous photolysis studies of the corresponding fluorenol derivatives. Computational data were also obtained to assess their thermodynamic stabilities.

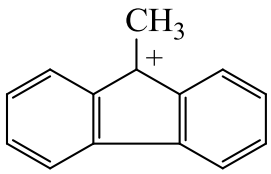

A

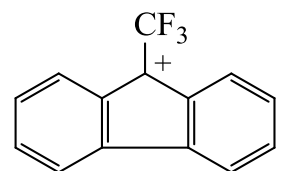

B

\section{Results and Discussion}

The starting photochemical precursors necessary for the fluorenyl cations are the corresponding 9-methylfluorenol (1a) and 9-trifluoromethyl fluorenol (1b) which were obtained from 9fluorenone. The former was obtained from methylation of 9-fluorenone with methyl magnesium bromide $^{5}$ while the latter was produced by reaction of 9-fluorenone with trifluoroacetophenone under basic conditions using a previously reported preparative trifluoromethylation procedure. ${ }^{6}$

\section{Photoproduct studies}

Irradiation of 9-trifluoromethylfluorenol (1b) in methanol solution $\left(2 \square 2.5 \times 10^{-3} \mathrm{M}^{-1}\right.$ ) for 0.5 hours led to two principal products, 9-trifluoromethylfluorene (3b) (19\%) and a dimer (17\%) which was assigned structure 5 based on spectral data. The mass spectrum showed a parent molecular ion at $\mathrm{m} / z=466.1$. The ${ }^{19} \mathrm{~F}-\mathrm{NMR}$ spectrum for $\mathbf{5}$ exhibited two signals, a singlet at $\delta=$ $-66.3 \mathrm{ppm}$ and a doublet at $\delta=-67.6 \mathrm{ppm}\left({ }^{3} \mathrm{~J}_{\mathrm{H}-\mathrm{F}}=9.3 \mathrm{~Hz}\right)$. The ${ }^{1} \mathrm{H}-\mathrm{NMR}$ spectrum for 5 displayed a quartet at $\delta=4.55 \mathrm{ppm}\left({ }^{3} \mathrm{~J}_{\mathrm{H}-\mathrm{F}}=9.3 \mathrm{~Hz}\right)$ for the $\mathrm{C}-9$ proton. In addition, the proton spectrum showed complex pattern of aromatic signals indicative of an asymmetrical fluorene substitution pattern from which a singlet $(1 \mathrm{H})$ at $\delta 7.76$ can be discerned. The latter suggests that the substitution at the asymmetric fluorene moiety is either at C-2 or C-3. The chemical shift of the uncoupled proton corresponds to that observed for C-4 rather than C-1 which would appear at lower fields due to the bay region deshielding effect (bay region proton appears at $\delta 7.8 \mathrm{ppm}$ in parent fluorene). Further support of the assignment comes from the 1D-NOE correlation between the C-9 proton with the peri-hydrogens at C-1 and C-8 both of which appear as doublets. Also C-3 would be expected to be the preferential site of attack for 9-fluorenyl radicals as a result of spin-delocalization. Interestingly, dimer $\mathbf{4 b}$ is formed as the major product when irradiation of $\mathbf{1 b}$ is carried out in benzene solutions. Bifluorene $\mathbf{4 b}$ exhibited a singlet for the ${ }^{19} \mathrm{~F}$ NMR spectrum and the characteristic aromatic proton signal pattern for 9-substituted fluorenes indicative of the symmetrical nature of the dimer. Final confirmation of the structure for $\mathbf{4 b}$ was obtained from its single crystal X-ray analysis (Figure 1) which shows the gauche conformation typical of bifluorenes, and an unusually long C9-C9' single bond length of $1.616 \AA$. 


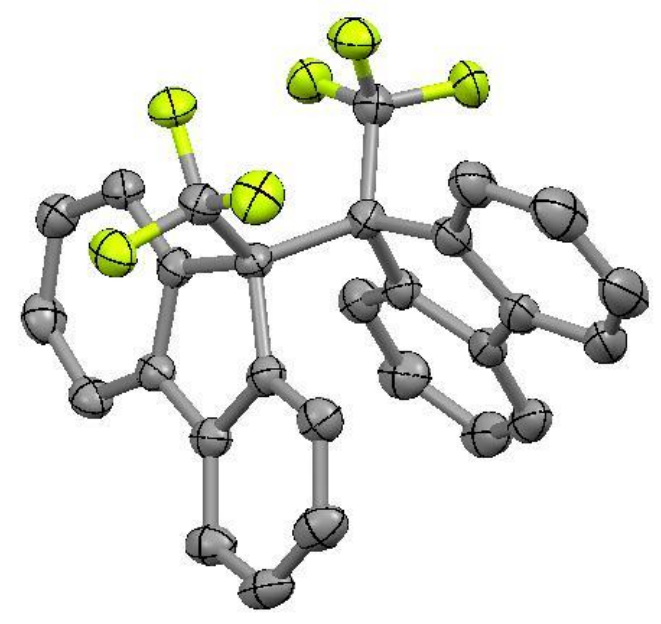

Figure 1. Single crystal structure of bifluorenyl $\mathbf{4 b}$.

Of note is the photoisomerisation of bifluorenyl $\mathbf{4 b}$ to $\mathbf{5}$ in methanol solutions which is unprecedented and may account for the formation of $\mathbf{5}$ in the photolysis of $\mathbf{1 b}$ in methanol. This photoisomerization also takes place with other polar solvents (ethanol, propanol, THF and acetonitrile) but not in less polar solvents (diethyl ether, benzene). The structure assignment for $\mathbf{3 b}$ is based on comparison with an authentic sample prepared by acid cyclization of $\alpha$-phenyl$\alpha$ (trifluoromethyl)benzenemethanol. ${ }^{7}$ A small amount $(<2 \%)$ of the photomethanolysis product 2b was evident from the NMR spectrum of the crude mixture and comparison with an authentic sample prepared from 9-trifluoromethylfluorenol (1b) by methylation of the alkoxide (prepared by sodium hydride deprotonation) with methyl iodide in THF. The remaining material from the photoreaction consisted of unreacted alcohol $\mathbf{1 b}(40 \%)$ and unidentified material.<smiles>[R]C1(O)c2ccccc2-c2ccccc21</smiles>

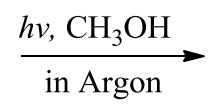

1a $\mathrm{R}=\mathrm{CH}_{3}$

$\mathbf{1 b} \mathrm{R}=\mathrm{CF}_{3}$<smiles>[R]C1(OC)c2ccccc2-c2ccccc21</smiles><smiles>[R]C1c2ccccc2-c2ccccc21</smiles>

3a $\mathrm{R}=\mathrm{CH}_{3}$

3b $\mathrm{R}=\mathrm{CF}_{3}$

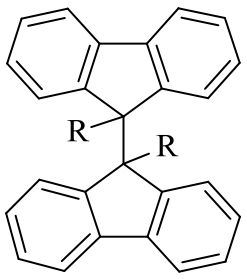

4a $\mathrm{R}=\mathrm{CH}_{3}$

$4 \mathbf{b ~ R}=\mathrm{CF}_{3}$<smiles>[R]C1c2ccccc2-c2cc(C3([R])c4ccccc4-c4ccccc43)ccc21</smiles> 
The low yield of ether $\mathbf{2 b}$ under the photolytic conditions is attributable to secondary photochemistry to produce $\mathbf{3 b}$ and $\mathbf{5}$ as shown from independent experiments. Evidence for the intermediacy of 9-trifluoromethyl carbocation in the photoexcitation of $\mathbf{1 b}$ is seen when this substrate is irradiated in 1,1,1,3,3,3-hexafluoroisopropanol (HFIP) with varying amounts of methanol. Decreasing amounts of methanol and shorter irradiation times led to an increase in the yields of $\mathbf{2} \mathbf{b}$ to the extent that it was the principal product in HFIP containing trace amounts of methanol. HFIP is known to stabilize carbocations by solvation effects as well as its unreactive nature as a nucleophile. ${ }^{8}$ Furthermore, HFIP is a relatively unreactive such that in the presence of adventitious methanol will not quench carbocations.

By contrast, irradiation of 9-methylfluorenol (1a) in methanol under the same conditions $(0.5$ hours, $\left.4.5 \times 10^{-3} \mathrm{M}\right)$ resulted in significantly larger amounts $(10 \%)$ of the photosolvolysis product 2a along with 9,9'-dimethyl-9,9'bifluorene 4a (17\%), 9-methylfluorene 3a (14\%) and 9 $\square$ fluorenone $(5 \%)$. Hydrocarbons $4 \mathbf{a}$ and $\mathbf{3 a}$ are products derived from radical pathways involving 9-fluorenyl radical. 9-Fluorenone is likely formed from oxygen quenching and autoxidation of 9-fluorenyl radical as was evident when purging the solutions with argon resulted in complete elimination of 9-fluorenone in the photolysate.

\section{Laser flash photolysis studies}

Solutions of alcohols $\mathbf{1 a}$ and $\mathbf{1 b}$ in HFIP $\left(8 \times 10^{-5} \mathrm{M}\right)$ were irradiated at $266 \mathrm{~nm}$ using a Nd:YAG laser with frequency quadrupling (Spectra-Physics Quanta-Ray $230 \mathrm{GCR}$ operating at $10 \mathrm{~Hz}$ ). Alcohols 1a and 1b showed transients with absorption maxima at $480 \mathrm{~nm}$ (shoulder at $450 \mathrm{~nm}$ ) and $560 \mathrm{~nm}$ (shoulder at $520 \mathrm{~nm}$ ), respectively (Figure 2). The corresponding lifetimes of the transients from $\mathbf{1 a}$ and $\mathbf{1 b}$ in HFIP are 36 and $5.4 \mu$ s, respectively.
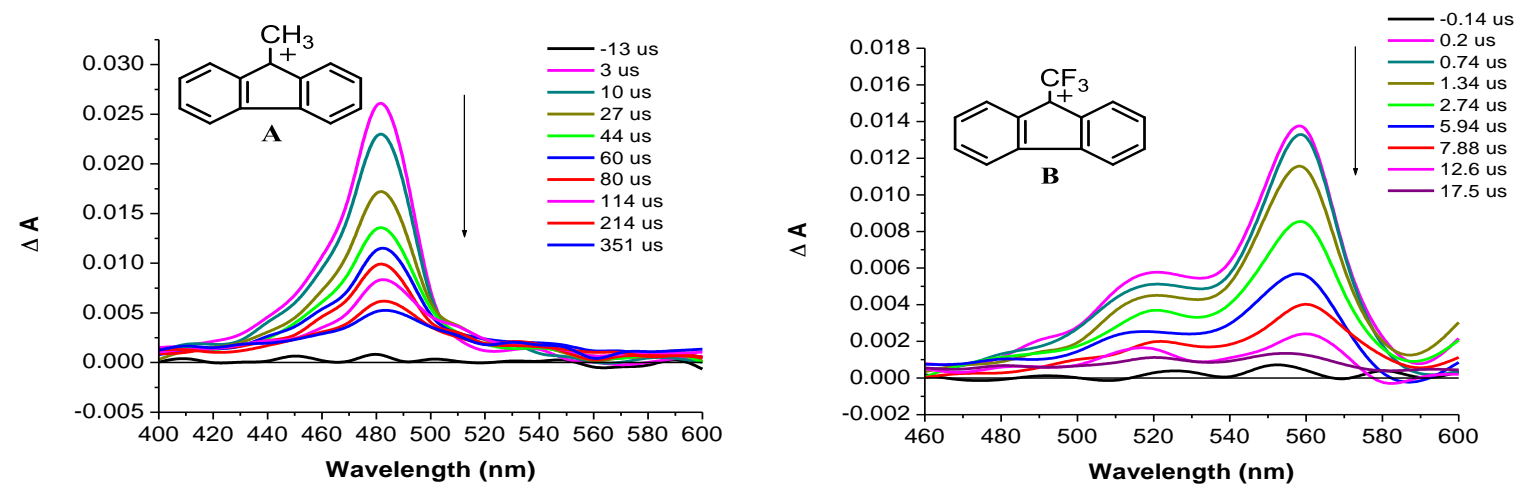

Figure 2. Transients from LFP of Alcohols 1a and $\mathbf{1 b .}$

These species were not affected by oxygen but were quenched with added methanol indicating cationic character and hence were assigned the structures $\mathbf{A}$ and $\mathbf{B}$. The bathochromic shift of the UV maximum in the presence of electron-withdrawing groups such as 
trifluoromethyl is a common phenomenon with carbocations or cationic species. ${ }^{11}$ The rate constants for reaction of cations $\mathbf{A}$ and $\mathbf{B}$ with methanol were determined by measuring the observed rates for decay ( $k_{\text {obs }}$ ) of the cations at $480 \mathrm{~nm}$ for $\mathbf{A}$ and $555 \mathrm{~nm}$ for $\mathbf{B}$ as a function of the concentration of added methanol. The data were fit according to eq 1 , where $k_{0}$ is the lifetime of the cations in the absence of quencher (Q). Methanol quenching of ions $\mathbf{A}$ and $\mathbf{B}$ occurred with rate constants $1.8 \times 10^{6} \mathrm{M}^{-1} \mathrm{~s}^{-1}$ and $1.0 \times 10^{8} \mathrm{M}^{-1} \mathrm{~s}^{-1}$, respectively, although direct comparison of these numbers are not accurate since 6a showed second order quenching kinetics (upward slope) with methanol while $\mathbf{B}$ gave first order linear behaviour. The second order quenching of fluorenyl cations with

$$
k_{o b s}=k_{0}+k_{q}[\mathrm{Q}]
$$

methanol has been previously observed and ascribed to a preformed solvated species followed by methanol deprotonation.

The relative lifetimes of cations $\mathbf{A}$ and $\mathbf{B}$ and the relative quenching rates with methanol suggest that $\mathbf{B}$ is significantly more reactive than $\mathbf{A}$. Nucleophile quenching of carbocations is affected by both steric and electronic factors. Since methyl and trifluoromethyl substituents are closely isosteric, ${ }^{13}$ differences in reactivities between $\mathbf{A}$ and $\mathbf{B}$ are likely due principally to electronic effects. The charges on the nucleofugal C-9 carbon for $\mathbf{A}$ and $\mathbf{B}$ were determined from theory (B3LYP) to be +1.20 and +0.83 , respectively, which would argue for $\mathbf{A}$ to be more reactive than $\mathbf{B}$. However, neighboring group effects may influence the kinetic reactivity as the methyl carbon in A has a charge of -0.16 whereas the trifluoromethyl carbon has a charge of +1.53 . The latter would enhance the nucleophilic approach of the quencher and result in the observed greater kinetic reactivity for $\mathbf{B}$.

\section{Computational studies (B3LYP level) of relative energies}

The relative stabilities of cations $\mathbf{A}$ and $\mathbf{B}$ along with the parent 9-fluorenyl cation were determined according to the standard equilibrium defining $\mathrm{pK}_{\mathrm{R}+}$ values (Scheme 1).

\begin{tabular}{ll} 
Scheme 1 \\
$\mathrm{R}$ & $\Delta \mathrm{G}^{0}$ Reaction $(\mathrm{kcal} / \mathrm{mol})$ \\
\hline $\mathrm{H}$ & -209.62 \\
$\mathrm{CH}_{3}$ & -218.62 \\
$\mathrm{CF}_{3}$ & -198.44 \\
\hline
\end{tabular}<smiles>[R]C1c2ccccc2-c2ccccc21</smiles>

\section{Scheme 1}


Table 1. Relative stabilities of 9-fluorenyl cations

\begin{tabular}{ll}
\hline $\mathrm{R}$ & $\Delta\left(\Delta \mathrm{G}^{0}\right)(\mathrm{kcal} / \mathrm{mol})$ \\
\hline $\mathrm{H}$ & 0 \\
$\mathrm{CH}_{3}$ & -9.0 \\
$\mathrm{CF}_{3}$ & +11.18 \\
\hline
\end{tabular}

As can be seen from Table 1 the trifluoromethyl substituent places an additional destabilization of about $11 \mathrm{kcal} \mathrm{mol}^{-1}$ relative to hydrogen whereas 9-methyl stabilizes the fluorenyl cation by $9 \mathrm{kcal} \mathrm{mol}^{-1}$. These values are consistent with the corresponding $\mathrm{pK}_{\mathrm{R}+\text { values }}$ for 9-fluorenyl and $\mathbf{A}$ of -15.9 and -11.1, respectively. ${ }^{2(\mathrm{~d})}$

\section{Conclusions}

The photolyses of 9-methyl-9-fluorenol (1a) and 9-trifluoromethyl-9-fluorenol (1b) in methanol give products which are principally derived from the corresponding radical intermediates. These include the corresponding bifluorenyl and photoreduced methyl- and trifluoromethylfluorenes. A small amount of photomethanolysis product was observed in each case indicating some photoheterolysis to the corresponding fluorenyl cations $\mathbf{A}$ and $\mathbf{B}$. These cations can be directly observed under time resolved laser flash spectroscopy in HFIP, a solvent known to stabilize carbocations. The corresponding transients are quenched with methanol indicating their electrophilic character. The lifetime of $\mathbf{B}$ is significantly shorter than for $\mathbf{A}$, and the kinetic reactivity as measured by the methanol quenching rates for $\mathbf{B}$ is significantly larger than for $\mathbf{A}$ pointing to the destabilized nature for the former. The thermodynamic stabilities obtained from theoretical calculations also point to the destabilizing nature for $\mathbf{B}$ brought about by the electronwithdrawing effect of the trifluoromethyl group.

The bifluorenes produced in the photolysis of $\mathbf{1 a}$ and $\mathbf{1 b}$ are likely the consequence of the dimerization of the fluorenyl radicals from photohomolysis. Of note is the observation of the unsymmetrical dimer $\mathbf{5}$ when photolysis of $\mathbf{1 b}$ is carried out in methanol solutions whereas $\mathbf{1 a}$ gives the symmetrical bifluorene 4a under the same conditions. The corresponding symmetrical dimer $\mathbf{4 b}$ is formed from $\mathbf{1 b}$ in less polar solvents. The bifluorenyl $\mathbf{4 b}$ is converted into $\mathbf{5}$ on irradiation in polar solvents. A systematic study of the photochemical behaviour of 9,9'disubstituted bifluorenes is currently underway.

\section{Experimental Section}

General. All reactions were done in dried glassware. All solvents used for the reactions were dried and distilled. Melting points were obtained with a Fisher-Johns melting point apparatus and 
are uncorrected. UV spectra were determined in $\mathrm{MeOH}$ solutions using an Ultraspec 4300 pro UV spectrometer. Infrared spectra were recorded on a Pye Unicam SP3-200 spectrometer as thin $\mathrm{KBr}$ pellets and are reported in $\mathrm{cm}^{-1}$. Mass spectra were recorded on a QStar Elite spectrometer. ${ }^{1} \mathrm{H}$-NMR, ${ }^{13} \mathrm{C}$-NMR and ${ }^{19} \mathrm{~F}$-NMR spectra were recorded on Bruker ARX $400 \mathrm{MHz}$ superconducting NMR spectrometer. Data for ${ }^{1} \mathrm{H}-\mathrm{NMR}$ are referenced relative to residual $\mathrm{CDCl}_{3}$ proton signals at $\delta 7.27 \mathrm{ppm}$ and to DMSO-d $\mathrm{d}^{6} \delta$ at $2.50 \mathrm{ppm}$. Data for ${ }^{13} \mathrm{C}-\mathrm{NMR}$ are referenced relative to $\mathrm{CDCl}_{3}$ at $\delta 77.16 \mathrm{ppm}$ and to DMSO-d $\mathrm{d}^{6} \delta$ at $39.52 \mathrm{ppm}$. Data for ${ }^{1} \mathrm{H}$ are reported as follows: chemical shift $(\mathrm{ppm})$, multiplicity $(\mathrm{s}=$ singlet, $\mathrm{d}=$ doublet, $\mathrm{t}=$ triplet, $\mathrm{q}=$ quartet, $\mathrm{h}=$ heptet, $\mathrm{m}=$ multiplet,) and integration. Analytical thin-layer chromatography (TLC) was performed on silica gel 60 ALUGRAM $^{\circledR}$ sheets and silica gel $(40-63 \mu \mathrm{m})$ was used for column chromatography. Preparative TLC was conducted using pre-dried glass plates coated with silica gel $(0-20 \mu \mathrm{m})$. All reagents employed were purchased from commercial sources and used without further purification. Photolyses were carried out using a Hanovia 450-W medium pressure mercury arc lamp in a water-cooled quartz immersion well. Quartz tubes containing the samples were strapped around this well, and the assembly was immersed in an ice-water bath. The samples were purged with argon for $30 \mathrm{~min}$ prior to irradiation.

\section{X-Ray diffraction analysis}

Data were collected on a Bruker-Nonius Kappa-CCD diffractometer using monochromated Mo$\mathrm{K} \alpha$ radiation and were measured using a combination of $\phi$ scans and $\omega$ scans with $\kappa$ offsets, to fill the Ewald sphere. The data were processed using the Denzo-SMN package. ${ }^{14}$ Absorption corrections were carried out using SORTAV. ${ }^{15}$ The structure was solved and refined using SHELXTL V6. $1^{16}$ for full-matrix least-squares refinement that was based on $F^{2}$. All $\mathrm{H}$ atoms were included in calculated positions and allowed to refine in riding-motion approximation with U iso tied to the carrier atom.

\section{Time resolved laser flash spectroscopy}

Nanosecond UV-visible laser flash photolysis spectrometer built at the Ohio Laboratory for Kinetic Spectrometry was used in the experiments. Frequency quadrupled $(266 \mathrm{~nm})$ pulses from a Spectra-Physics Quanta-Ray $230 \mathrm{GCR}$ operating at $10 \mathrm{~Hz}$ were used for excitation. The pulse energy was $0.5-0.7 \mathrm{~mJ}$; the pulse duration was ca. $7 \mathrm{~ns}$. The samples were placed in an open top $10 \times 10 \times 45 \mathrm{~mm}^{3}$ rectangular quartz cuvette with four clear windows. Sample solutions were deoxygenated by purging with argon for 20-30 minutes prior to and during the photolysis. The transient absorption was monitored using a white light probe beam placed at right angles to the laser beam. The probe beam from a $150 \mathrm{~W} \mathrm{cw} \mathrm{Xe} \mathrm{arc} \mathrm{lamp} \mathrm{was} \mathrm{focused} \mathrm{through} \mathrm{the} \mathrm{sample} \mathrm{and}$ re-imaged onto the entrance slit of a SPEX $1681(0.22 \mathrm{~m})$ monochromator. The monochromatic light was then detected with a modified (5- instead of the original 9-stage dynode amplifier) R928 PMT obtained from Hamamatsu (response time $<2 \mathrm{~ns}$ ). To prevent the PMT detector from overexposure, a fast shutter (Uniblitz) was set up at the output of the Xe lamp. The combination of the output spectral irradiance from the white light source, the detector spectral response, and 
the optics transmittance provided the spectrometer's spectral window between ca. 300 and ca. $800 \mathrm{~nm}$ with the linear dispersion of $4 \mathrm{~nm} \mathrm{x} \mathrm{mm}^{-1}$.

The signals from the PMT detector were routed through a DC-coupled back-off circuit which stored and displayed digital readout for the constant component of the signal $\left(\mathrm{I}_{0}\right)$, and provided a compensating offset to it. The real-time current was fed into a DC-coupled vertical channel of a Tektronix TDS-380 digital oscilloscope (400 MHz bandwidth) with a 50 Ohm input impedance. The overall time response of the electronic data acquisition system was ca. $2.5 \mathrm{~ns}$, and the time frame covered was up to $2 \mathrm{~ms}$.

The UV-visible flash photolysis spectrometer was computer-controlled using in-house National Instrument LabVIEW software. Timing pulses to trigger the laser flash lamps and Q-switch, the fast shutter, the back-off, and the oscilloscope were generated using the National Instrument PCTIO counter/timer card. The data from the oscilloscope, representing an average of up to 256 laser shots at the $5 \mathrm{~Hz}$ repetition rate, were transferred to the computer via the GPIB interface, processed (converted into $\triangle \mathrm{OD}$ units) and stored in a file. The typical sensitivity of the spectrometer was ca. $5 \times 10^{-4}$ OD with 16 -shot averaging. Kinetics at a desired wavelength or the full spectral and kinetic data acquisition could be performed. In the latter case the output of the routine was recorded as a 3D (time, wavelength, transient signal amplitude) transient absorption surface incorporating complete spectral and kinetic data. This surface was then scrutinized with standard data analysis software packages like SigmaPlot, Origin, etc.

\section{Computational methods}

Trial geometries were obtained using the MMFF94 molecular mechanics force field ${ }^{17}$ as implemented in the SPARTAN software[2]. ${ }^{18}$ These trial geometries were then optimized within Density Functional Theory (DFT) by a standard method with the G03 Gaussian software[3]. ${ }^{19}$ We performed the calculations with the B3LYP hybrid exchange-correlation functional[5]. ${ }^{20}$ Dunning-Huzinaga double zeta basis sets[6] ${ }^{21}$ (keyword: LANL2DZ) were used. We took a finer grid (G03 keyword: Ultrafine) for B3LYP calculations. The harmonic frequencies, which we calculated for all species, confirmed that the geometries are minima in all cases. They were used for calculating free energies at $298 \mathrm{~K}$ which include the zero-point energy and the usual estimates for PV and TS based on a ideal gas model. The energies of reactions that we report are differences in free energies between products and reactants.

As suggested by a reviewer, we repeated all calculations with a triple zeta basis set. Specifically, we used keyword cc-pTZV in Gaussian, which invokes the triple zeta basis of Dunning et al. ${ }^{22}$ Going from LANL2DZ to the larger basis set caused all energies to be reduced, by an amount that varies between 0.5 and 5.5 of reaction $\mathrm{kcal} / \mathrm{mol}$. Changes in energies of reaction for Scheme 1 using the larger basis set associated with $\mathrm{R}=\mathrm{H}$ to $\mathrm{CH}_{3}$ and $-\mathrm{CF}_{3}$ substitutions are smaller than $2 \mathrm{kcal} / \mathrm{mol}$ from the original values in all cases resulting in minor differences in stabilities (from Table 1 the energy differences for $\mathrm{R}=\mathrm{CH}_{3}$ and $\mathrm{R}=\mathrm{CF}_{3}$ using the larger basis set are -9.1 and +9.4 $\mathrm{kcal} / \mathrm{mol}$, respectively). 
The atomic charges we report were obtained from a population analysis based on atomic polar tensors (APT). ${ }^{23}$ In essence, the APT charge on an atom " $\mathrm{j}$ " is the rate of change of the molecular dipole moment with respect to a displacement of atom " $\mathrm{j}$ ". Unlike Mulliken charges, APT charges do not depend explicitly on the basis set.

\section{9-Methyl-9-Fluorenol (1a)}

The title compound was prepared from 9-fluorenone and methylmagnesium bromide according to a literature procedure. ${ }^{5}$

\section{9-Trifluoromethyl-9-fluorenol (1b)}

The title compound was prepared by a slightly modified reported method. ${ }^{6}$ 9-Fluorenone $(6 \mathrm{~g}$, $0.032 \mathrm{~mol}$ ) was dissolved in $11.5 \mathrm{~mL}$ of DMF. To this solution was added 1-phenyl-2,2,2trifluoroethanone $(3.1 \mathrm{~mL})$ with stirring. This was followed by addition of $2.3 \mathrm{~g}(0.021 \mathrm{~mol})$ of potassium tert-butoxide in $15 \mathrm{~mL}$ THF under argon and the reaction was left to stir for $20 \mathrm{~min}$. The mixture was neutralized with $1 \mathrm{M} \mathrm{HCl}$ in ether $(23 \mathrm{~mL})$ and left stirring overnight. The reaction mixture was extracted with $50 \mathrm{~mL}$ ether and washed with water. The ether layer was dried by addition of anhydrous $\mathrm{Na}_{2} \mathrm{SO}_{4}$ and evaporated under reduced pressure. The residue was chromatographed on a silica gel column (ether:hexane, $1: 10)$ giving a white solid $(2.2 \mathrm{~g}, 31 \%)$, m.p. 81-83 ${ }^{\circ} \mathrm{C}$ (lit. ${ }^{24}$ m.p 83-85 $\left.{ }^{\circ} \mathrm{C}\right)$.

\section{Photolysis of 1a and 1b. General procedures}

Fluorenols 1a and 1b (50 to $100 \mathrm{mg}$ ) were dissolved in 80-160 mL spectrograde methanol and irradiated for $30 \mathrm{~min}$. Following evaporation of the solvent the residue was purified by preparative thin layer chromatography (ethyl acetate : hexane, 1:15)

\section{Photoproducts from 1a:}

From $75 \mathrm{mg}$ of $1 \mathbf{a}$ on preparative TLC (3\% diethyl ether/hexane) was obtained $8 \mathrm{mg} \mathbf{2 a}, 11 \mathrm{mg}$ of $\mathbf{3 a}, 13 \mathrm{mg}$ of $\mathbf{4 a}, 3 \mathrm{mg}$ of 9-fluorenone and $30 \mathrm{mg}$ of unreacted material.

9-Methyl-9-methoxyfluorene (2a). M.p. 88-90 ${ }^{0} \mathrm{C}$ (lit. ${ }^{25}$ m.p $86{ }^{0} \mathrm{C}$ ); ${ }^{1} \mathrm{H}-\mathrm{NMR}: \delta 7.67$ (d, 2H, J $=2.77, \mathrm{~J}=7.3 \mathrm{~Hz}$ ), $7.51(\mathrm{~d}, 2 \mathrm{H}, \mathrm{J}=7.2 \mathrm{~Hz}), 7.40-7.28$ (Two overlapping triplets, $4 \mathrm{H}), 2.77(3 \mathrm{H}$, s), $1.72(3 \mathrm{H}, \mathrm{s})$. Spectrum similar to that reported. ${ }^{25}$

9-Methylfluorene (3a). Waxy solid (lit. ${ }^{26}$ m.p. $45-46{ }^{0} \mathrm{C}$ ); ); ${ }^{1} \mathrm{H}-\mathrm{NMR}$ : $\delta 7.85$ (d, 2H, J = 7.16 $\mathrm{Hz}$ ), 7.55 (d, 2H, J = 7.0 Hz), 7.43-7.28 (two overlapping triplets, 4H), 3.99 (1H, q, J = 7.3 Hz), $1.58(\mathrm{~d}, 3 \mathrm{H}, \mathrm{J}=7.3 \mathrm{~Hz})$.

9,9'-Dimethyl-9,9'-bi-9H-fluorene (4a). M.p. 210-212 ${ }^{0} \mathrm{C}$ (lit. ${ }^{27}$ m.p. $209-211{ }^{0} \mathrm{C}$ ); ${ }^{1} \mathrm{H}-\mathrm{NMR}$ : $\delta 7.40(\mathrm{~d}, 4 \mathrm{H}, \mathrm{J}=7.5 \mathrm{~Hz}), 7.22$ (t, 4H, J = 7.4 Hz), 7.05 (t, 4H, J = 7.35 Hz), 6.90 ( br.d, 4H), $1.94(\mathrm{~s}, 6 \mathrm{H})$. 


\section{Photoproducts from $1 \mathrm{~b}$}

From $100 \mathrm{mg}$ of $\mathbf{1 a}$ on preparative TLC (3\% diethyl ether/hexane) was obtained $20 \mathrm{mg} \mathbf{3 b}, 21$ $\mathrm{mg}$ of $\mathbf{5}, 30 \mathrm{mg}$ of unreacted material. A trace amount of $\mathbf{2 b}$ was observed in the ${ }^{1} \mathrm{H}-\mathrm{NMR}$ spectrum vide infra.

9-Trifluoromethylfluorene (3b). M.p. $95-97{ }^{0} \mathrm{C}$ (lit. ${ }^{7}$ m.p. $95-97{ }^{0} \mathrm{C}$ ); ${ }^{1} \mathrm{H}-\mathrm{NMR}: \delta 7.80(\mathrm{~d}, 2 \mathrm{H}, \mathrm{J}$ $=7.5 \mathrm{~Hz}), 7.73(\mathrm{~d}, 2 \mathrm{H}, \mathrm{J}=7.5 \mathrm{~Hz}), 7.50(\mathrm{t}, 2 \mathrm{H}, \mathrm{J}=7.5 \mathrm{~Hz}), 7.41(\mathrm{t}, 2 \mathrm{H}, \mathrm{J}=7.5 \mathrm{~Hz}), 4.42(1 \mathrm{H}, \mathrm{q}$, $\mathrm{J}=9.4 \mathrm{~Hz}) .{ }^{19} \mathrm{~F}-\mathrm{NMR}: \delta-67.73(\mathrm{~d}, \mathrm{~J}=9.6 \mathrm{~Hz})$. GCMS: $\mathrm{mz}=234\left(\mathrm{M}^{+}=234\right)$. Identical in all respect with a sample previously prepared in this lab. ${ }^{7}$

3-(9'-Trifluoromethyl-9H-fluorenyl)-9-trifluoromethylfluorene (5). M.p. $67-69{ }^{\mathbf{0}} \mathrm{C} ;{ }^{1} \mathrm{H}-\mathrm{NMR}$ : $\delta 7.83(\mathrm{~d}, 2 \mathrm{H}, \mathrm{J}=7.7 \mathrm{~Hz}), 7.76(\mathrm{~s}, 1 \mathrm{H}), 7.68(\mathrm{t}, 2 \mathrm{H}, \mathrm{J}=8.0 \mathrm{~Hz}), 7.60-7.48(\mathrm{~m}, 5 \mathrm{H}), 7.45(\mathrm{t}, 1 \mathrm{H}$, $\mathrm{J}=7.6 \mathrm{~Hz}), 7.40-7.32(\mathrm{~m}, 3 \mathrm{H}), 7.22(\mathrm{~d}, 1 \mathrm{H}, \mathrm{J}=8.1 \mathrm{~Hz}), 4.55(\mathrm{q}, \mathrm{H}, \mathrm{J}=9.3 \mathrm{~Hz}) ;{ }^{19} \mathrm{~F}-\mathrm{NMR}$ :

$\delta-65.3(\mathrm{~s}),-67.62(\mathrm{~d}, \mathrm{~J}=9.3 \mathrm{~Hz})$; GCMS: $m z=466\left(\mathrm{M}^{+}\right)$; Anal. Calc for $\mathrm{C}_{28} \mathrm{H}_{16} \mathrm{~F}_{6}: \mathrm{C}, 72.10 ; \mathrm{H}$, 3.46; F, 24.44. Found: C, 72.29; H, 3.56; F, 23.75.

\section{Photolysis of $1 \mathrm{~b}$ in benzene}

A solution of $150 \mathrm{mg}$ of $\mathbf{1 b}$ in $120 \mathrm{~mL}$ of benzene was irradiated for $1 \mathrm{~h}$. The solution was evaporated to give a residue which was separated by preparative TLC (ethyl acetate:benzene, 1:10) giving 9-trfluoromethylfluorene $\mathbf{3 b}(29.2 \mathrm{mg}$, 20\%) identical to a sample identified above, and dimer $\mathbf{4 b}(32.6 \mathrm{mg}, 21 \%)$ in addition to $40 \mathrm{mg}$ of unreacted $\mathbf{1 b}$.

9,9'-Ditrifluoromethyl-9,9'-bi-9H-fluorene (4b). M.p (recrystallized from warm hexane): 143$145{ }^{0} \mathrm{C} ;{ }^{1} \mathrm{H}-\mathrm{NMR}: \delta 7.40(\mathrm{~d}, 4 \mathrm{H}, \mathrm{J}=7.41 \mathrm{~Hz}), 7.30(\mathrm{t}, 4 \mathrm{H}, \mathrm{J}=7.2 \mathrm{~Hz}), 7.25$ (br.d, 4H, J = 7.4 $\mathrm{Hz}), 7.70(\mathrm{t}, 4 \mathrm{H}, \mathrm{J}=7.2 \mathrm{~Hz}) ;{ }^{19} \mathrm{~F}-\mathrm{NMR}: \delta-62.2(\mathrm{~s})$; GCMS: $m z=466\left(\mathrm{M}^{+}\right), 233\left(\mathrm{M}^{+} / 2\right)$; Anal. Calc for $\mathrm{C}_{28} \mathrm{H}_{16} \mathrm{~F}_{6}$ : C, 72.10; H, 3.46; F, 24.44. Found: C, 72.09; H, 3.40; F, 24.25. See Fig. 1 for ORTEP diagram of single crystal structure.

\section{Preparation of authentic 9-methoxy-9-trifluoromethylfluorene (2b)}

A solution containing $\mathbf{1 b}(50 \mathrm{mg}, 0.2 \mathrm{mmol})$ in $2 \mathrm{~mL}$ of THF was cooled to $0{ }^{0} \mathrm{C}$ and stirred under argon. To this solution was added sodium hydride $(15 \mathrm{mg})$ and the solution was stirred for $10 \mathrm{~min}$ at $0{ }^{0} \mathrm{C}$. To this solution was added $342 \mathrm{mg}$ of methyl iodide $(0.24 \mathrm{mmol})$ and the reaction mixture was left to stir overnight at room temperature. The solution was evaporated under reduced pressure and the residue applied on a silica gel column (hexane). A colourless crystalline compound was obtained of $\mathbf{2 b}(50 \mathrm{mg}, 94 \%)$. M.p. $65-67{ }^{0} \mathrm{C} ;{ }^{1} \mathrm{H}-\mathrm{NMR}: \delta 7.70$ (d, $2 \mathrm{H}, \mathrm{J}=7.51 \mathrm{~Hz}), 7.67(\mathrm{~d}, 2 \mathrm{H}, \mathrm{J}=7.0 \mathrm{~Hz}), 7.51(\mathrm{t}, 2 \mathrm{H}, \mathrm{J}=7.4 \mathrm{~Hz}), 7.40(\mathrm{t}, 4 \mathrm{H}, \mathrm{J}=7.50 \mathrm{~Hz})$, 2.93 (s, 3H); ${ }^{19} \mathrm{~F}-\mathrm{NMR}: \delta-77.0$ (s); Anal. Calc for $\mathrm{C}_{15} \mathrm{H}_{11} \mathrm{~F}_{3} \mathrm{O}: \mathrm{C}, 68.18 ; \mathrm{H}, 4.17 ; \mathrm{F}, 21.59$. Found: C, 67.95; H, 4.25; F, 21.25. 


\section{Photolysis of $1 \mathrm{~b}$ in HFIP with adventitious methanol}

Alcohol $\mathbf{1 b}(50 \mathrm{mg})$ in $5 \mathrm{~mL}$ HFIP with $0.1 \mathrm{~mL}$ of methanol was irradiated for $30 \mathrm{~min}$. The solution was evaporated and the residue was applied to preparative TLC separation giving $8 \mathrm{mg}$ of $\mathbf{2 b}$ identical in all respect with a sample prepared above, and $35 \mathrm{mg}$ of unreacted $\mathbf{1 b}$.

\section{Photolysis of $\mathbf{4 b}$ in $\mathrm{CD}_{3} \mathrm{OD}$}

Bifluorene $4 \mathbf{b}(5 \mathrm{mg})$ in $2 \mathrm{~mL}$ of methanol was placed in an NMR tube. The solution was irradiated for $30 \mathrm{~min}$ and the ${ }^{1} \mathrm{H}-\mathrm{NMR}$ and ${ }^{19} \mathrm{~F}-\mathrm{NMR}$ spectra recorded indicating a $30 \%$ conversion to dimer 5.

\section{Acknowledgements}

We would like to thank NSERC for financial support.

\section{References}

1. (a) Abboud, J.-L. M.; Alkorta, I.; Davalos, J. Z.; Muller, P.; Quintanilla, E.; Rossier, J.-C. J. Org. Chem. 2003, 68, 3786. (b) Della, E. W.; Schiesser, C. H. J. Chem. Soc., Chem. Commun. 1994, 417.

2. (a) Allen, A.; Tidwell, T. T. Chem. Rev. 2001, 101, 1333. (b) Mecklenburg, S. L.; Hilinski, E. F. J. Am. Chem. Soc. 1989, 111, 5471. (c) McClelland, R. A.; Mathivanan, N.; Steenken, S. J. Am. Chem. Soc. 1990, 112, 4857. (d) Amyes, T.; Richard, M.; Novak, M. J. Am. Chem. Soc. 1992, 114, 8032. (e) Jia, H.; Schleyer, P. v. R.; Mo, Y.; McAllister, M. A.; Tidwell, T. T. J. Am. Chem. Soc. 1997, 119, 7075. (f) Rodriquez, C. F.; Vukovic, D. L.; Hopkinson, A. C. J. Mol. Structure (THEOCHEM) 1996, 363, 131. (g) Mladenova, G.; Singh, G.; Acton, A.; Chen, L.; Rinco, O.; Johnston, L. J.; Lee-Ruff, E. J. Org. Chem. 2004, 69, 2017. (h) Mladenova, G.; Chen, L.; Rodriquez, C. F.; Siu, K. W. M.; Johnston, L. J.; Hopkinson, A. C.; Lee-Ruff, E. J. Org. Chem. 2001, 66, 1109.

3. Creary, X.; Hopkinson, A. C.; Lee-Ruff, E. Advances in Carbocation Chemistry 1989, 1, 4.

4. (a) Allen, A.; Tidwell, T. T. J. Org. Chem. 2001, 66, 7696. (b) Allen, A.; Fujio, M.; Mohammed, N.; Tidwell, T. T.; Tsuji, Y. J. Org. Chem. 1997, 62, 246-252. (c) Lew, C. S. Q.; Wong, D. F.; Johnston, L. J.; Bertone, M.; Hopkinson, A. C.; Lee-Ruff, E. J. Org. Chem. 1996, 61, 6805-6808. (d) Allen, A.; Colomvakos, J. D.; Tee, O. S.; Tidwell, T. T. J. Org. Chem. 1994, 59, 7185. (e) Johnston, L. J.; Kwong, P.; Shelemay, A.; Lee-Ruff, E. J. Am. Chem. Soc. 1993, 115, 1664. (f) Fletcher, D.; Ablenas, F. J.; Hopkinson, A.C.; Lee-Ruff, E. Tetrahedron Lett. 1986, 27, 4853.

5. Friedrich, E. C.; Taggart, D. B. J. Org. Chem. 1978, 43, 805.

6. Jablonski, L.; Billard, T.; Langlois, B. R. Tetrahedron Letters 2003, 44, 1055.

7. Dao, L. H.; Maleki, M.; Hopkinson, A. C.; Lee-Ruff, E. J. Am. Chem. Soc. 1986, 108, 5237. 
8. McClelland, R. A.; Mathivanan, N.; Steenken, S. J. Am. Chem. Soc. 1990, 112, 4857.

9. Liu, Y.; Ballweg D.; Muller, T.; Guzei, A. I.; Clark, R. W.; West, R. J. Am. Chem. Soc. 2002, 124, 12174.

10. Dougherty, D. A.; Llort, F. M.; Mislow, K.; Blount, J. F. Tetrahedron 1978, 34, 1301.

11. (a) Hopkinson, A. C.; Lee-Ruff, E.; Toone, T.; Khazanie, P.; Dao, L. J. Chem. Soc., Perkin Trans. 2 1979, 1395. (b) Atkinson, A.; Hopkinson, A. C.; Lee-Ruff, E. J. Chem. Soc., Perkin Trans. 2 1972, 1854. (c) Grocock, D. E.; Hallas, D.; Hepworth, J. D. J. Chem. Soc., Perkin Trans. 2 1973, 1792.

12. Bancerz, M.; Huck, L. A.; Leigh, W. J.; Mladenova, G.; Najafian, K.; Zeng, X.-F.; Lee-Ruff, E. J. Phys. Org. Chem. 2010, 23, 1202.

13. Vilchis-Reyes, M. A.; Zentella, A.; Martinez-Urbina, M. A.; Guzman, A.; Vargas, O; Ramirez Apan, M. T.; Ventura Gallegos, J. L.; Diaz, E. Eur. J.Med. Chem. 2010, 45, 379.

14. Otwinowski, Z.; Minor, W. Methods in Enzymology, 1997; Vol. 276, Macromolecular Crystallography, Part A, Carter, C. W.; Sweet, R. M. Academic: London pp 307-326.

15. Blessing, R. H. Acta Cryst. 1995 A51, 33-38.

16. Sheldrick, G. M., SHELXTL/PC. Version 6.1 Windows NT Version. Bruker AXS Inc., Madison, USA, 2001.

17. Halgren,T.A. J. Comput. Chem. 1996, 17, 490.

18. Hehre, W. J.; Yu, J.; Klunzinger, P. E. A Guide to Molecular Mechanics and Molecular Orbital Calculations in Spartan, Wavefunction Inc., 1997.

19. Gaussian 03, Revision C.02, M. J. Frisch et al., Gaussian, Inc., Wallingford CT, 2004.

20. Becke, A.D. J. Chem. Phys., 1993, 98, 5648.

21. Dunning Jr., T.H.; Hay, P. J. In Modern Theoretical Chemistry, Schaefer III, H. F., Ed. Plenum: New York, 1976; Vol. 3, pp 1-28.

22. (a) Dunning Jr. T. H. J. Chem. Phys. 1989, 90, 1007. (b) Kendall, R. A.; Dunning Jr., T. H.; Harrison, R. J. J. Chem. Phys. 1992, 96, 6796.

23. Cioslowski, J. J. Am. Chem. Soc.1989, 111, 8333.

24. Sibille, S.; Mcharek, S. M.; Perichon, J. Tetrahedron 1989, 45, 1423.

25. Wan, P.; Krogh, E. J. Am. Chem. Soc. 1989, 111, 4887.

26. Harvey, R.; Fu, P. P.; Rabideau, P. W. J. Org. Chem. 1976, 41, 2706.

27. Werry, J.; Stamm, H.; Sommer, A. Chem. Ber. 1990, 123, 1553. 